\title{
INVESTIGATION OF THE FACTORS AFFECTING ROLE STRESS OF CHEMICAL INDUSTRY MANAGERS IN TURKEY
}

\author{
*Hülya GÜNDÜZ ÇEKMECELİOĞLU \\ Kocaeli University, Turkey
}

\begin{abstract}
The aim of this study is to examine the stress perceptions experienced by managers of chemical industry, specifically how role ambiguity and role conflict are related to autonomy, challenging job, personorganization fit and supportive top management. In this vein, a survey is conducted on 247 first and middle line managers of three chemical firms located around Kocaeli, Turkey. In order to test the interrelationship among the given antecedents and role stressors, we performed a structural equation modeling analysis. The results indicate that both person-organization fit and supportive top management are directly and negatively related to role ambiguity while challenging job is directly and negatively related to both role ambiguity and role conflict. Limitations as well as theoretical and managerial implications are discussed.
\end{abstract}

Keywords: Role Stress,Role Ambiguity, Autonomy, Person-Organization Fit

\section{INTRODUCTION}

Globalization, competition, advancements in information technology, increased work demands, decreasing resources, a changing workforce, and transformations in the expectations and capabilities of employees result with higher levels of stress that should be effectively managed (Dupre and Day, 2007). Based on Role Theory, researchers have focused on role conflict and role ambiguity as the two key determinants of role stress. Role conflict refers to 'the degree of incongruity or incompatibility of expectations associated with a role while role ambiguity is an employee's uncertainty about others' expectations. The perceived incompatible job expectations (role conflict) and the uncertainty about the others' expectations (role ambiguity) makes it difficult, for the employees to decide how best to meet and to accomplish their tasks concurrently (Kagan, 1972; Widmer, 1993). Thus role stress has long been a concern for researchers and practitioners as it has deleterious effects on individuals' mental and physical health, as well as negative effects on organizational outcomes such as low performance, and efficiency (Rizzo et al., 1970; Fisher and Gitelson, 1983; Yousef, 2000). Moreover, the previous studies strongly underline the negative effects of role stress on job satisfaction organizational commitment and intention to remain of employees (Tubre and Collins, 2000; Moore, 2000; Mohr and Puck, 2007; Wu and Norman, 2006).

A review of the role theory suggests that most of the studies are mainly focused on the outcomes of the role stress while only a few has addressed the inducing effects of organizational context or the factors on both role ambiguity and role conflict (Rizzo et al., 1970; Fisher and Gitelson, 1983; Yousef, 2000; Mohr and Puck, 2007; Wu and Norman, 2006). Therefore, studying role stress and potential means of reducing the negative effects of role stressors of employees is an important subject that may contribute to our understanding of the antecedents of role stressors.

This study is focused on the effects of organizational context or work environment on role stress at a broader organizational level. We considered to take the work environment characteristics as the potential antecedents of role stressors in terms of supportive management, challenging job, autonomy, person-organization fit and investigated their effects on perceptions towards role stress. To test the relationships among work environment characteristics and role stressors (role ambiguity and role conflict), we conduct a survey on the 
first line and middle managers of three large sized companies operating in chemical industry. We expect the findings of this study to contribute to role theory by addressing the effects of work environment characteristics on perceived role ambiguity and role conflict, from an empirical view.

\section{BACKGROUND AND HYPOTHESIS DEVELOPMENT}

\section{Role Stressors}

Since role stress has significant influences on both individuals and organizations, it has been one of the important subjects in the organizational behavior literature. Based on Role Theory, researchers have focused on role conflict and role ambiguity as the two key determinants of role stress. In their expansive treatment of roles in organizations, Kahn et al. (1964) define role as the activities expected of a person (the role incumbents) in a particular job or position, and stated several forces influencing this role. Firstly, the role is influenced by each of the other roles or positions (referred to as the role set) with which he or she interacts. Secondly, the role set holds various proscriptions and prescriptions that are labeled as the role expectations. Thirdly, members of the role set attempt to induce the role incumbent to bring about the role set's expectations (labeled as the role pressures). Kahn et al. (1964) argue that these pressures give rise to role stress, in the form of role ambiguity and role conflict (Schulz and Auld, 2006; 186.).

Role ambiguity represents a condition resulting from uncertain information about role behavior (Kahn et al., 1964). Uncertainty can arise from complex organizational structures and poor communication with respect to an individual's duties, authority, and allocation of time to tasks and relationships with others. Thus, according to role theory, ambiguity should increase the probability that a person will be dissatisfied with his role, will experience anxiety, will distort reality and will thus perform less effectively (Rizzo et al., 1970; 151). Role conflict refers to inconsistent job obligations, incompatibility in the requirements of the role or the degree to which work demands from two or more people are incompatible (Rizzo et al., 1970).

Pandey and Kumar (1997) state that role conflict can be divided into three parts: First, individuals experience inter-role conflicts when the expectations associated with different roles which the individual plays are incompatible with one another. For example, the expectations associated with the individual's role as manager (e.g. to work overtime) may conflict with the expectations engaged with the individual's role as father or mother (e.g. leave work early). Second, intra-role conflicts are experienced if the different expectations associated with a single role conflict with one another. Third, individuals may also experience person-role conflicts if the expectations associated with one of the individual's roles are incompatible with the person's own needs, aspirations, and/or values: a manager, for instance, may be expected to bribe officials in order to acquire contracts which may conflict with his/her values (Mohr and Puck, 2007; 26). Role theory states that, when the behaviors expected of an individual are inconsistent-one kind of role conflict- he will experience stress, become dissatisfied, and perform less effectively than if the expectations imposed on him did not conflict. Role conflict can therefore be seen as resulting from violation of the two classical principles and causing decreased individual satisfaction and decreased organizational effectiveness (Rizzo et al., 1970; 151). In sum, the body of research, conducted in different kind of organizational settings, indicate that high degrees of role ambiguity and role conflict are associated with undesirable consequences for both organization and members (Kahn et al., 1964; Smith, 1957; Gross et al., 1958 Mohr and Puck, 2007; Wu and Norman, 2006; Rizzo et al., 1970; Wu and Norman, 2005; Yang 2010; Tubre and Collins, 2000).

\section{The Factors Affecting Role Stress}

The OB indicates that employees' perceptions of the organizational context or work environment are the determinants of employee behaviors such as creativity (Amabile et al, 1996), job satisfaction, intention to leave (Shalley et al., 2000), organizational commitment (Gündüz Çekmecelioðlu, 2011). In general role stress is considered as a negative situation and some researchers claim that the application of mechanistic or classical organizational structure in the form of formalization of practices and processes reduced role 
ambiguity (House and Rizzo, 1972; Johnson and La France, 1998). On the other hand, literature is abound of contradictory evidence related with the have positive outcomes of role ambiguity under specific circumstances. For instance, Yoshioka, (1990) suggested that role ambiguity facilitated the adaptation to changing conditions, and contributed to managerial and organizational flexibility and increased employee participation. Similarly, Hage and Aiken (1967) came to a conclusion that the more involved professional staff were within the organization, the more likely the organization would have a decentralized power structure and particularly for some occupations, formalization increased role ambiguity (Schulz and Auld, 2006; 186).

In conclusion, in OB literature it is widely held that job characteristics and social relationships (Fisher and Gitelson 1983) or organizational design, structure and individuals' characteristics and communication processes (Kahn et al. 1964) effect role ambiguity. In this study we decided to take the job characteristics as the potential antecedents of role stressors in terms of supportive management, challenging, job, autonomy, person-organization fit and investigated their effects on perceptions towards role stress. These characteristics will be described based on a comprehensive literature review and hypothesis will be developed in the following sections.

\section{Supportive Top Management}

Supportive management style allows subordinates to try and fail without fear of reprisals. It also gives them control over their work and the methods they use to accomplish it (Brown and Leigh, 1996). Supportive top managers also keep informed about how employees think and feel about things, also allow employees to make decisions about work on their own, encourage employees to participate in important decisions, to speak up when they disagree. They also explain their actions to employees, help employees solve work-related problems and encourage them to develop new skills. They praise good work and reward good performance but refrain from always checking on employee's work (Cummings and Oldham, 1997). Humborstad and Kuvaas (2013) claimed that, subordinates had low role ambiguity and low intrinsic motivation when leaders' and subordinates' empowerment expectations were met at low levels and when leaders underestimated subordinates' empowerment expectations. However, subordinates had low role ambiguity and high intrinsic motivation when expectations were met at high levels. Furthermore, role ambiguity was high and intrinsic motivation was low when the leaders overestimated subordinates' empowerment expectations. In contrary, a few researches on the determinants of the role stress points out that supportive management style and high quality leader-member-exchange seems to diminish the negative effects of role stress (Cummings, 1990; Orpen, 1982; Muchinsky, 1997; Jex, 1998). Therefore, it's likely that managers who encourage risk taking and idea generation and provide positive informational feedback, substantial freedom and autonomy at work, opportunities to influence important decisions, supervisory interactions, have negatively affect role stressors. Accordingly;

H1: There is a negative relationship between supportive top management and role stressors

\section{Autonomy}

The extent to which individuals can schedule their tasks, determine what actions are required, and decide how best to execute their actions are considered to be important for their satisfaction related to their jobs. Formalization in some particular occupations is found to increase role ambiguity. In this context formalization is perceived as directive control over work which conflicts with the expectations of specialized employees such as managers requiring autonomy and creativity (Schulz and Auld, 2006; 188). The more perceived autonomy, the more responsible the individual will feel for the outcomes (Lankau et al., 2006; 311) Moreover, perceived autonomy is positively linked to lower levels of stress and greater job satisfaction (Dubinsky and Skinner, 1984). Therefore;

$\mathrm{H} 2$. There is a negative relationship between autonomy and and role stressors 


\section{Challenge}

Challenge reflects an individual's desire to be stimulated by the job; it can be quantified as the degree that the job requires a variety of skills (Allen et al., 2008; 551). Challenging work induces employees to invest greater amounts of their physical, cognitive, and emotional resources in their work and is likely to result in greater perceived meaningfulness of the work experience (Brown and Leigh, 1996; 360). Furthermore, challenging and complex jobs provide employees the freedom to focus simultaneously on multiple dimensions of their work and permit them to conduct their activities without external controls or constraint (Oldham and Cummings, 1996). Especially specialized employees tend to be more satisfied with work and more eager to make more of an effort when it is challenging rather than boring (Brown and Leigh, 1996, 361; Gündüz Çekmecelioðlu, 2006). Therefore, chemical industry managers have a high need for challenging work. The opportunity of challenging work is intrinsically satisfying. Consequently it's observed that characteristics of challenging jobs have positively affected intrinsic motivation of employee and creativity (Amabile et al., 1996; Shalley et al., 2000; Oldham and Cummings, 1996). Accordingly;

$\mathrm{H} 3$. There is a negative relationship between job-related challenge and their perceived role stressors

\section{Person-Oragization Fit}

Kristof (1996) defined P-O fit as "the compatibility between people and organizations that occurs when: (a) at least one entity provides what the other needs, or (b) they share similar fundamental characteristics, or (c) both"). P-O fit attenuates job stressors, such as role ambiguity and role conflict (Parkington and Schneider, 1979) which, in turn, facilitates job performance (Tubre and Collins, 2000). Furthermore, employees will feel more motivated and less stressed if they feel their job is interesting and when there is a fit between individual and organizational values and job requirements (Meglino et al., 1989; 426). Thus;

H4. There is a negative relationship between P-O fit and role stressors.

\section{METHODOLOGY}

\section{Measures}

To test the above hypotheses, multi-item scales adopted or developed from prior studies for the measurement of the constructs are used. All constructs are measured using 5-point Likert scales ranging from 'strongly disagree' (1) to 'strongly agree' (5). Supportive top management by 7 items adopted from studies of Amabile et al. (1996) and Oldham and Cummings (1997). Autonomy is measured using three items from Amabile et al.s (1996) autonomy scale. Similarly, challenging job is measured using four items from the study of Amabile et al. (1996). Person- organization fit is measured with four items, which adopted from scales of Netemeyer et al. (1997). Role stress is measured using six items- three for role ambiguity and three for role conflict- from Rizzo et al.`s (1970) role stress scale.

\section{Sampling}

After developing the new question items in English, three academics graduated from US based universities, evaluated the content and meaningfulness of the items to establish face validity. They did not note any difficulty in understanding the items or scales. These new and adopted question items were first translated into Turkish by one person and then retranslated into English by a second person using the paralleltranslation method. The two translators then jointly reconciled all differences. A draft questionnaire was developed and then evaluated and revised in discussions with academics from Turkey, with knowledge of organizational behavior and innovation as expert judges. The suitability of the Turkish version of the questionnaires was then pre-tested by five part-time graduate students who are full-time employees working in industry. Respondents did not demonstrate any difficulty understanding the items or scales. After confirming the questionnaire items, the questionnaires were distributed and collected by the authors, applying the "personally administrated questionnaire" method. 
The sampling population consists of 600 employees of the three large sized manufacturing firms operating in chemical industry located around Kocaeli. The firms were selected because they were at the first 500 list of Istanbul Chamber of Commerce since 5 year. In addition, these firms (i) are organized and managed based on a Western management style, e.g., they operate in accordance with ISO and European quality standards, and (ii) they are exporting their products to Western companies such as Germany, UK, Spain. First, we contacted the firms' General Managers by telephone and explained the aim of the study to them. Then we sent 200 surveys to the each firm and asked for first line and middle managers who are the most knowledgeable about the organization's operations, financial situation, culture, and employees, to fill out our survey. After qualifying the respondents, we informed each that his/her responses would remain anonymous and would not be linked to them individually, nor to their companies, or products. This was done to assure anonymity, thus increasing the motivation of informants to cooperate without fear of potential reprisals. In addition, we assured respondents that there were no right and wrong answers and that they should answer questions as honestly and forthrightly as possible. These procedures reduced the evaluation apprehension and made the subjects less likely to edit their responses to be more socially desirable, lenient, and consistent with how they think the researchers wanted them to respond (Podsakoff et al., 2003).

Of the 600 managers asked to participate, 282 agreed and completed our questionnaires. However, 35 surveys had missing values, resulting in 247 surveys. Thus, our analyzable sample consisted of 247 employees of three firms. In our sample, the respondents were senior first line managers (78\%); middle managers (22\%). The mean age of the participants were 33.27(s.d.=5.58); the proportion of women, $11 \%$, and married $69,5 \%$. Of the participants, $\% 37$ had post graduate education.

\section{Analysis and Results}

\section{Measure Validity and Reliability}

We evaluated the reliability and validity of our constructs using confirmatory factor analysis (CFA) (Anderson and Gerbing, 1988; Fornell and Larcker, 1981). By using AMOS 4.0, we investigated all six constructs (involving 25 question items) in one CFA model by use of all surveys ( $\mathrm{N}=247)$. One item from the role ambiguity and person-organization fit scale tended to cross-load on other factors. An examination of these items revealed that deleting them would not deteriorate the content validity of the role ambiguity and person-organization fit. Therefore, we dropped one of the role ambiguity and person-organization fit items. After the elimination of these two items, the resulting measurement model was found to fit the data reasonably well: the resulting measurement model was found to fit the data reasonably well: $\chi 2(330)=698,1$, Comparative Fit Index $(\mathrm{CFI})=.91$, Incremental Fit Index $(\mathrm{IFI})=.91$, Tucker-Lewis Index $(\mathrm{TLI})=.90 \chi 2 / \mathrm{df}$ $=2.12$, and root-mean-square error of approximation RMSEA $=0.067$ and $($ RMSEA $)=0.071$. In addition, all items loaded significantly on their respective constructs (with the lowest $t$-value being 2.50), providing support for convergent validity.

Table 1 reports the reliabilities of the multiple-item, reflective measures, along with construct correlations and descriptive statistics for the scales. Table 1 shows that there are a moderate correlations among the person-organization fit variables (such as, $\mathrm{r}=.514$ ). However, we should note that we were expecting these scores, because, in practice, for instance, the fit between personal values and organizational dynamics is highly related to the management style and job characteristics.. Our CFA and discriminant validity analysis also shows that they are statistically separate constructs.

Table 1. Descriptive statistics, correlations and composite reliabilities

Table 1 also demonstrates that all AMOS 4.0 based composite reliabilities are well beyond or close to the threshold levels suggested by Nunnally (1978) and Fornell and Larcker (1981). After conducting these tests, we conclude that our measures have adequate discriminant and convergent validity. 


\section{Hypothesis Testing}

To test our hypotheses, we performed a multiple linear regression model and structural equation modeling (SEM). The results of the path analysis are shown at Table 2. The results indicate that supportive top management negatively affects the role ambiguity $(\beta=-0,141, \mathrm{p}<.05)$, partially supporting H1. Challenge negatively effects both role ambiguity $(\beta=-0,624, p<.01)$ and role conflict $(\beta=-0,731, p<.01)$, supporting H3. Moreover, the results demonstrates person-organization fit is negatively associated with role ambiguity ( $\beta=$ $0,484, \mathrm{p}<.01$ ), partially supporting H4. However, the results do not provide any empirical evidence in support of the direct relationships between autonomy and role stressors.

Table 2. Path analysis

\begin{tabular}{|c|c|c|c|c|c|c|c|c|c|c|}
\hline & & Mean & St.d & $\begin{array}{l}\text { Composite } \\
\text { reliability }\end{array}$ & 1 & 2 & 3 & 4 & 5 & 6 \\
\hline $\begin{array}{l}\text { Supportive top } \\
\text { management }\end{array}$ & 1 & 3,54 & 847 & 0,82 & -- & & & & & \\
\hline Autonomy & 2 & 3,25 & 879 & 0,78 &, $522 * *$ & -- & & & & \\
\hline Challenge & 3 & 4,23 & ,668 & 0,89 &, $380 * *$ &, $314 * *$ & -- & & & \\
\hline Person-Org. Fit & 4 & 3,51 & 877 & 0,90 &, $451 * *$ &, $514 * *$ &, $456 * *$ & -- & & \\
\hline Role ambiguity & 5 & 2,19 & 1,191 & 0,76 &,$- 146^{*}$ &,$- 144 *$ &,$- 245^{* *}$ &,$- 197 * *$ & -- & \\
\hline Role conflict & 6 & 2,59 & 1,108 & 0,84 &,- 101 &,- 115 &,$- 290 * *$ &,$- 188 * *$ &, $350 * *$ & -- \\
\hline
\end{tabular}

\begin{tabular}{ll}
\hline Path & â \\
\hline Supportive top management $\rightarrow$ Role ambiguity &,$- 141^{*}$ \\
Autonomy $\rightarrow$ Role ambiguity &,- 028 \\
Challenge $\rightarrow$ Role ambiguity &,$- 624 * *$ \\
Person-organization fit $\rightarrow$ Role ambiguity &,$- 484 * *$ \\
Supportive top management $\rightarrow$ Role conflict &, 146 \\
Autonomy $\rightarrow$ Role conflict &,- 024 \\
Challenge $\rightarrow$ Role conflict &,$- 731^{* *}$ \\
Person-organization fit $\rightarrow$ Role conflict &,- 112 \\
\hline
\end{tabular}

Also, our results indicate that work environment characteristics explains the $32 \%$ of variance $(\mathrm{R} 2=.32)$ in the role ambiguity, and $13 \%$ of variance $(\mathrm{R} 2=.13)$ in the role conflict.

\section{CONCLUSION}

Most of the previous studies indicate that stress has important effects on personal and organizational outcomes while underestimating the organizational and managerial regulations in general, work environment characteristics in particular to overcome the role stress. This research offers a contribution to OB literature by presenting a model of interrelationships among work environment -in terms of supportive top management, 
autonomy, challenge and person-organization fit- and role stress. By highlighting the role of work environment characteristics in influencing role stress perceptions, this study offers a framework for researchers and practitioners to visualize and understand the ways to induce perceived role stress through work environment characteristics, thus enhancing the movement of Role Theory in the OB literature. This study, specifically, makes four contributions to the literature.

First the findings of this study essentially show that a managerial style that empowers and supports the employees and is closely related to the role stress perceptions. Generally, positive treatments from the top management towards employees are perceived as evidence that the organization cares about its employees and recognizes their contributions. Indeed supportive management is a communication centered approach which includes providing employees sufficient information about their roles as well as freedom and support. Specifically the positive attitudes and behaviors of the top management, such as recognizing and respecting the ideas of the employees, encouraging them to take initiative, and providing feedback, may create a work environment in which employees can understand their roles and tasks clearly in a more focused manner. As a consequence, employees at any hierarchical level are more likely to experience less stress.

Second this study investigates the effects of challenging job on the role stressors. The findings suggest that the more challenging work results with the less degrees of role ambiguity and role conflict. This means that when the jobs and tasks are complicated to a certain extent, employees require more freedom, independence, and discretion in carrying out them. So the employees feel clearer about the content and boundaries of their roles and tasks. And when the employees are clear about their own and their co-workers` roles and tasks, in addition to the less intervention from the top managers and customers, the conflicts related to their tasks probably lessen or even disappear. Thus, challenging work results with less ambiguity and conflict. Also when the tasks are more challenging, individuals pay more attention on carrying out them. The higher levels of attention may lead to higher levels of motivation and performance as well.

Third, the results show that the congruence of personal and organizational values has an inducing influence on role ambiguity. Person organization fit refers to transparent organizations having particular values, and employing the right individuals concerning these values, with an effective knowledge sharing mechanism. In this sense, person-organization fit would provide organization-wide shared values and perceptions that result with less uncertainty and anxiety. Hence employees are more likely to feel more confidence. This result is especially important for managers and researchers who want to build and develop a work environment that prevents the role stressors.

Surprisingly, this study provides no empirical evidence in support of the relationships between autonomy and role stressors. This does not mean that autonomy has no relationship with role stressors; rather autonomy may influence the role stressors via other job characteristics due to the significant covariance among them. Moreover, this interesting result considering autonomy may be caused by the internal dynamics of the chemical industry Chemical industry is a competitive industry at its mature stage. In such mature industries, there are clear and well-established hierarchical systems providing formal rules and procedures and guides. In this sense, employees are not encouraged to take initiatives; rather they are expected to follow the welldefined patterns, shelving the autonomy. So employees are more certain about the content and boundaries of their tasks and are not to face incompatible role expectations of managers, customers and co-workers. This interesting result questions the widely held assumption which considers autonomy as a universal solution.

From this research, the implications for managers are three-fold. First, top management should design and nurture a communication centered work environment where employees at any hierarchical level i) are safe to interact with the management as well as each other without feeling rejected or punished, ii) can receive feedback about their past behaviors and performance, iii) can participate the decision making process and iv-) can feel that their efforts and contributions are recognized. Also, management should foster an ongoing dialogue and interactions among employees at after-work meetings and parties to develop an informal 
communication mechanism in order to build and develop a work environment that lessens the stress perceptions.

Second, management should realize the importance of the job design and take the necessary steps to design the job to be challenging and interesting rather than boring. Based on the fact that challenging jobs are likely to stimulate motivations and result in greater perceived meaningfulness of the work experience, management should look new ways to make the jobs and tasks more challenging.

Third, management should attach importance in employing new individuals; as the results strongly recommend that person-organization fit plays a significant role in lessening the stress perceptions. So management should deepen the recruitment process in general, and highlight the personality tests within the recruitment process in particular. Moreover, management should also establish and promulgate an organizational culture in accordance with its employees`norms and values.

The findings of this study, however, should be tempered with an understanding of the conditions in which the research was conducted. First, this study is conducted on large sized firms; so the results reflect the behavioral and perceptional patterns of large sized firms. Second, these results reported here emerge from a local area; results may differ for firms located on different areas, operating under different cultural, environmental and political conditions. Third, the sample is composed of employees of the firms operating in chemical industry in general mature industries in particular; results may differ for different industries at different stages of the industrial life cycle. Despite these limitations, this study provides important implications from theoretical and practical perspectives. Our findings help to open the black box of the antecedents of role stressors in large sized firms and shed light on how to induce the stress perceptions through the job characteristics. This study also contributes to the Role Theory by suggesting that supportive top management, challenging job and P-O fit can help to build a mechanism to fight the role stress, particularly in large sized firms in which the employees are most likely to be drawn in stress. This research just scratches the surface of this important, but understudied subject. Future researchers will find the area of the antecedents of the role stress rich and fruitful for OB literature. 


\section{REFERENCES}

Allen, M.W., Armstrong, D.J., Reid, M.F. and Riemenschneider, C.K. (2008), "Factors impacting the perceived organizational support of IT employees", Information \& Management, Vol. 45, pp.556-563.

Amabile, T. M., Conti, R., Coon, H., Lazenby, J. and Herron, M. (1996), Assessing The Work Environment For Creativity. Academey of Management Journal, 39(5), pp.1154-1184.

Anderson, J.C. and Gerbing D.W. (1988), Structural Equation Modeling in Practice: A Review and Recommended Two - Step Approach. Psychological Bulletin, 103, pp.411-423.

Brown S. P. and Leigh T. W. (1996), A New Look at Psychological Climate and Its Relationship to Job Involvement, Effort, and Performance. Journal of Applied Psychology, 81(4), pp.358-368.

Cummings A. and Oldham G.R. (1997), Enhancing Creativity: Managing Work for the High Potential Employee. California Management Review, 40(01), pp.22-38.

Cummings W.K., (1990), The culture of effective science: Japan and the United States. Minerva, 28(4), pp.426-445.

Çekmecelioğlu, H. G., (2011), Algılanan Örgüt İkliminin Çalışanların İş Tatmini, Duygusal Bağlılık ve Örgütsel Vatandaşlık Davranışı Üzerindeki Etkilerinin İncelenmesi. Yönetim, 22 (68), ss.29-47.

Çekmecelioðlu, H. G., (2006), Ýp Tatmini ve Örgütsel Baðlýlýk Unsurlarýnýn Yaratýcýlýk Üzerindeki Etkileri. Ýktisat Ýpletme ve Finans, 21, ss.120-131.

Dubinsky, A. J. and Skinner, S. J. (1984), Impact of Job Characteristics on Retail Salespeople's Reactions to Their Jobs. Journal of Retailing, 60(2), pp.35-62.

Dupre, K. E. and Day, A. L. (2007), The Effects of Supportive Management and Job Quality on the Turnover Intentions and Health of Military Personel. Human Resource Management, 46(2), pp.85-201.

Fisher, C. and Gitelson, R. (1983), A Meta-Analysis of the Correlates of Role Conflict and Role Ambiguity. Journal of Applied Psychology, 68, pp.320-333.

Fornell, C. and Larcker, D.F., (1981), Evaluating structural equation models with unobservable variables and measurement error. Journal of Marketing Research, 18 (1), pp.39-50.

Gross, Neal, Ward S. Mason, and Alexander W. McEachern, (1958), Explorations in Role Analysis. New York: Wiley.

Hage, J. and Aiken, M., (1967), Relationship of Centralization to Other Structural Properties. Administrative Science Quarterly, 12(1), pp.72-92.

House, R. and Rizzo, J. (1972), Role conflict and ambiguity as critical variables in a model of organizational behavior. Organizational Behavior and Human Performance, 7, pp.467-505.

Humborstad, S. I. W., and Kuvaas, B. (2013), Mutuality in leader-subordinate empowerment expectation: Its impact on role ambiguity and intrinsic motivation. The Leadership Quarterly, (24), pp.363-377.

Jex, S. M.(1998), Stress and job performance: Theory, research, and implications for managerial practice. Thousand Oaks, CA: SAGE Publications.

Johnson, J., and La France, B. (1998), The impact of formalization, role conflict, role ambiguity and communication quality on perceived organizational innovativeness in the cancer information service. Evaluation and the Health Professions, 21(1), pp.27-51.

Kagan J, (1972), The psychologists, Oxford University Press.

Kahn, R. L., Wolfe, D. M., Quinn, R. P., Snoek, J. D., and Rosenthal, R. A. (1964), Organizational Stress: Studies in Role Conflict and Ambiguity. New York: Wiley. 
Kristof, A. L., (1996), Person-Organizatýon Fýt: An Integratýve Revýew of its Conceptualýzatýons, Measurement, and Implýcatýons. Personnel Psychology, 49(1), pp.1-49.

Lankau, M., Carlson, D.S. and Nielson, T.R. (2006), The mediating influence of role stressors in the relationship between mentoring and job attitudes. Journal of Vocational Behavior, 68, pp.308-322.

Meglino, B. M., Ravlin, E. C. and Adkins, C. L., (1989), A Work Values Approach to Corporate Culture: A Field Test of The Value Congruence Process and its Relationship to İndividual Outcomes. Journal of Applied Psychology, 74(3), pp.424-432.

Mohr A. T. and Puck J. F., (2007), Role Conflict, General Manager Job Satisfaction and Stress and the Performance of IJVs. European Management Journal, 25(1), pp.25-35.

Moore, J. E. (2000), One Road To Turnover: An Examination of Work Exhaustion in Technology Professionals, MIS Quarterly, 24/ 1, pp.141-168.

Muchınsky, Paul M. (1997), Psychology Applied To Work. Itp, Company.

Netemeyer RG, Boles JS, McKee DO, McMurrian R. (1997), An investigation into the antecedents of organizational citizenship behaviors in a personal selling context. Journal of Marketing, 61(3), pp.85-98.

Nunnally, J. C. (1978), Psychometric Theory. New York, NY: McGraw-Hill.

Oldham, G. R., and Cummings, A. (1996), Employee creativity: Personal and contextual factors at work. Academy of Management Journal, 39, pp.607-634.

Orpen, C., (1982), Student Versus Lecturer Assessment of Learning: A Research Note. Higher Education, 11(5), pp.567-572.

Pandey, S. and Kumar, E.S. (1997), "Development of a measure of role conflict", International Journal of Conflict Management, Vol. 8 No. 3, pp.187-215.

Parkington, J. P., and Schneider, B. (1979,. Some correlates of experienced job stress. A boundary role study. Academy of Management Journal, 22, pp.270-281.

Podsakoff, P. M., MacKenzie, S. B., Lee, J.-Y., and Podsakoff, N. P. (2003), Common method biases in behavioral research: A critical review of the literature and recommended remedies. Journal of Applied Psychology, 88, pp.879-903.

Rizzo, J.R., House, R.J. and Lirtzman, S.I., (1970), Role Conflict and Ambiguity in Complex Organizations. Administrative Sciences Quarterly, 15, pp.150-163.

Schulz, J. and Auld, C., (2006), Perceptions of Role Ambiguity by Chairperson and Executive Officers in Queensland Sporting Organisations. Sport Management Review, 9, pp.183-202.

Shalley, C.E., Gilson, L.L., and Blum TC. (2000), Matching creativity requirements and the work environment: Effects on satisfaction and intentions to leave, Academy of Management Journal 43, pp.215223.

Smith, E. E. (1957), The effects of clear and unclear role expectations on group productivity and defensiveness. Journal of Abnormal and Social Psychology, 55, pp.213-217.

Tubre, T. C. and Collins, J. M., (2000), A Meta-Analysis of the Relationships Between Role Ambiguity, Role Conflict, and Job Performance. Journal of Management 26, pp.155-169.

Widmer, C ., (1993), Role Conflict, Role Ambiguity, and Role Overload on Boards of Directors of Nonprofit Human Service Organizations. Nonprofit and Voluntary Sector Quarterly. 22 (4), pp.339-356. 
Wu, L. and Norman I.J., (2006), An Investigation of Job Satisfaction, Organizational Commitment and Role Conflict and Ambiguity, In A Sample of Chinese Undergraduate Nursing Students. Nurse Education Today, 26(4), pp.304-314.

Yang, J. T., (2010), Antecedents and Consequences of Job satisfaction In the Hotel Industry. International Journal of Hospitality Management, 29 (2010), pp.609-619.

Yoshioka, C. (1990), Organizational motives of public, non-profit, and commercial leisure service agencies. Journal of Applied Recreation Research, 15, pp.59-70.

Yousef, D. A. (2000), The Interactive Effects of Role Conflict and Role Ambiguity on Job Satisfaction and Attitudes Toward Organizational Change: A Moderated Multiple Regression Approach. International Journal of Stress Management, 7, pp.289-303. 